OPEN ACCESS

Edited by:

Jianjun Chen,

University of Florida, United States

Reviewed by:

Shaojun Xie,

Purdue University, United States

Yongrui Wu,

Shanghai Institutes for Biological

Sciences (CAS), China

Rentao Song,

China Agricultural University, China

L. Curtis Hannah,

University of Florida, United States

*Correspondence:

David R. Holding

dholding2@unl.edu

Specialty section:

This article was submitted to

Plant Breeding,

a section of the journal

Frontiers in Plant Science

Received: 03 July 2018 Accepted: 20 November 2018 Published: 06 December 2018

Citation:

Ren Y, Yobi A, Marshall L, Angelovici $R$, Rodriguez $O$ and

Holding DR (2018) Generation and Evaluation of Modified Opaque-2 Popcorn Suggests a Route to Quality

Protein Popcorn.

Front. Plant Sci. 9:1803. doi: 10.3389/fpls.2018.01803

\section{Generation and Evaluation of Modified Opaque-2 Popcorn Suggests a Route to Quality Protein Popcorn}

\author{
Ying Ren ${ }^{1,2}$, Abou Yobi ${ }^{3}$, Leandra Marshall1,2, Ruthie Angelovici3 ${ }^{3}$, Oscar Rodriguez ${ }^{1}$ and \\ David R. Holding ${ }^{1,2 *}$
}

${ }^{1}$ Department of Agronomy and Horticulture, University of Nebraska - Lincoln, Lincoln, NE, United States, ${ }^{2}$ Center for Plant Science Innovation - Beadle Center for Biotechnology, University of Nebraska, Lincoln, NE, United States, ${ }^{3}$ Division of Biological Sciences and Interdisciplinary Plant Group, University of Missouri, Columbia, MO, United States

Introducing traits from dent corn to popcorn is challenging because it is difficult to recover adequate popping characteristics. QPM (Quality Protein Maize) is a dent corn variety carrying the opaque-2 (02) mutation, specifying increased amounts of normally limiting essential amino acids, and modifier genes which restore the wild type vitreous kernel phenotype. In this study, we introgressed 02 and selected for endosperm modification using vitreousness and high $27-\mathrm{kD}$ gamma zein content. In this way, we recovered high-lysine, fully poppable Quality Protein Popcorn (QPP). $\mathrm{BC}_{2} \mathrm{~F}_{4}$ individuals with vitreous kernels were confirmed to be 02 mutants by both genotyping and SDSPAGE. Amino acid profiling of $\mathrm{BC}_{2} \mathrm{~F}_{4}$ individuals showed that they all have significantly increased lysine compared with popcorn parental lines. Principal Component Analysis of the amino acid profiles showed that all introgressions were grouped with corresponding QPM parental lines. Popping analysis of the $\mathrm{BC}_{2} \mathrm{~F}_{5}$ individuals showed that while there is variability in popping volume between lines, some lines show equivalent popping to the popcorn parent. In this proof-of-concept study for QPP, we have shown that it is possible to rapidly recover sufficient popcorn characteristics in a modified 02 background using simple phenotypic, biochemical and genetic selection. Furthermore, this shows increased $\gamma$-zein is an acceptable substitute for $\alpha$-zein for full poppability. Since we have developed multiple QPP introgressions, this gives good scope for ongoing hybrid production and future evaluation of agronomic performance and selection of elite hybrids. In a wider context, this study shows the potential for breeding beneficial traits into popcorn for agronomic improvement.

Keywords: popcorn, QPM, opaque-2, lysine, maize-breeding, zein

\section{INTRODUCTION}

Maize a major cereal crop ranking number one is in the world in grain production. Like other cereals, it is nutritionally imbalanced, as the dominant seed storage proteins, the zeins, are devoid of two essential amino acids, lysine, and tryptophan. Compared with the optimal amount required for human nutrition which is $5 \%$ lysine and $1.1 \%$ tryptophan, respectively, maize grain contains 
only $1.5-2.5 \%$ lysine and $0.25-0.5 \%$ of tryptophan (Young et al., 1998). The opaque-2 (o2) mutant which has kernels with reduced zein content and increased lysine content (Mertz et al., 1964) offered potential as a more complete source of plant protein. However, o2 mutant kernels have soft endosperm, increased susceptibility to fungal pathogens and mechanical damage and grain yield is reduced. Quality Protein Maize (QPM) was developed by breeding 02 mutants with normal kernel hardness and vitreousness while retaining the high lysine content. The nutritional benefits of QPM were confirmed in feeding trials (Sofi et al., 2009; Panda et al., 2010; Mbuya et al., 2011).

Several QPM conversions have been performed in dent corn (Babu et al., 2005; Manna et al., 2005; Collard and Mackill, 2008; Surender et al., 2017). Introgression of the opaque-2 gene without modifier genes into popcorn backgrounds was carried out in several studies where popping was not maintained (Zhou et al., 2016; Adunola, 2017). To date, there have not been any reports of QPM conversion for popcorn lines that have maintained popping. In fact, introgression of any dent corn trait to popcorn was rarely reported. Dent corn $\times$ popcorn crosses were made mainly for mapping studies of quality trait QTLs for popcorn improvement such as higher yielding hybrids and popping expansion volume (PEV) (Dofing et al., 1991). The development of Quality Protein Popcorn (QPP) is challenging because it requires full QPM conversion but with the added challenges resulting from popcorn maintaining Ga1-s locus and recovering acceptable popcorn quality.

Breeding for QPM requires introgression of both the $o 2$ allele and multiple unlinked modifier quantitative trait loci (QTLs). Availability of $\mathrm{O} 2$ in-gene and flanking markers can facilitate the introgression process of the o2 allele (Babu et al., 2005; Babu and Prasanna, 2014; Surender et al., 2014; Kostadinovic et al., 2016; Krishna et al., 2017). The difficulties encountered in QPM conversion projects result from restoring kernel vitreousness because of the complexity of modifier QTLs. Several mapping studies were carried out and QTLs for modifiers (in terms of kernel vitreousness and density) were mapped on Chromosomes 1, 5, 7, and 9 (Holding et al., 2008, 2011; Babu et al., 2015). Multiple lines of evidence suggest that an increase in gene expression and protein accumulation of $27-\mathrm{kD} \gamma$-zein plays a major role in modification in QPM and this gene resides within the major QTL on Chromosome 7 (Geetha et al., 1991; Holding et al., 2008; Wu et al., 2010; Holding, 2014). The characteristic increase has been used as a biochemical marker for endosperm modification in QPM. Recently, it was verified that the $27-\mathrm{kD}$ $\gamma$-zein protein increase is conferred by a duplication event at 27$\mathrm{kD} \gamma$-zein locus (Liu et al., 2016). Causal genes within other QTLs remain unknown. As a result, QPM conversion still relies heavily on phenotypic selection of endosperm modification although the $27-\mathrm{kD} \gamma$-zein genetic and biochemical markers are very useful.

Comparison between the B73 genome and the popcorn landrace Palomero Toluqueno revealed that Palomero genome is 22\% smaller yet with larger predicted gene number being around 58,000, compared with 50,000 for B73 (Walbot, 2008; Schnable et al., 2009; Vielle-Calzada et al., 2009). Popcorn usually carries cross-incompatibility genes (known as gametophyte factors) that prevent popcorn from being fertilized by pollen of dent corns. This has been exploited for propagation of popcorn since it need not be grown in isolation from transgenic hybrid corn. Maintenance of Gal-s is required in popcorn breeding programs. Additionally, breeding for popcorn improvement and trait introgression into popcorn germplasm requires maintenance of $\mathrm{PEV}$. Studies mapping $\mathrm{PEV}$ in several dent $\times$ popcorn populations indicate multiple and variable QTLs (Dhliwayo, 2008; Li et al., 2007, 2009) and show the complexity of PEV. Introgression of dent traits into popcorn backgrounds is hindered by dent alleles with negative effects on PEV.

A previous QPM breeding program adopted both foreground (for o2) and background selection using MAS (marker-assisted selection) and developed QPM conversion lines within two backcrossing generations (Babu et al., 2005; Kostadinovic et al., 2016). MAS has not been widely used in selection of modifier genes because regions delineated as modifier QTLs tend to be large genetic intervals and highly variable in effect. The most significant QTL, 27-kD $\gamma$-zein duplication, is common across all QPMs and can now be used as a foreground marker (Liu et al., 2016). Also, the fact that mapping studies of modifier QTLs had been limited to specific QPM germplasms, might suggest that other minor effect QTLs are not common across all QPMs. This may restrict the application of MAS in projects such as this one in which multiple introgressions from different QPMs were performed.

In this study, we initiated QPP development with three QPMs and 11 popcorn lines. We aimed to introgress o2 from QPM to popcorn germplasms while maintaining Ga1-s, endosperm modification, popcorn kernel shape and popping ability. Since the correlation between kernel vitreousness and popping expansion is high (Hoseney et al., 1983; Erazo-Barradas, 2009), selection on the basis of kernel vitreousness was expected to result in simultaneous selection for PEV. Analysis of resultant $\mathrm{BC}_{2} \mathrm{~F}_{4}$ and $\mathrm{BC}_{2} \mathrm{~F}_{5}$ populations including lightbox selection, zein profiling, amino acid profiling, and quantitative popping tests were carried out. We developed multiple QPP inbreds from which hybrid production is now in progress. These results represent a breakthrough in the introgression of traits from dent corn into popcorn and show the general potential for popcorn improvement.

\section{MATERIALS AND METHODS}

\section{Plant Materials}

The 11 elite popcorn lines, whose identities are withheld, were provided by ConAgra. For QPM lines, K0326Y, is a tropical QPM inbred line developed in South Africa by Hans Gevers (Gevers and Lake, 1992). The other 11 QPMs were from North Central Regional Plant Introduction Station.

\section{Total Zein Extraction}

Zeins and non-zeins were extracted according to an established method (Wallace et al., 1990). Briefly, kernels for analysis were ground into flour. $50 \mathrm{mg}$ flour was incubated overnight in $1 \mathrm{ml}$ borate extraction buffer (with $2 \% \quad \beta$-mercaptoethanol) with shaking at room temperature. After centrifugation at 
room temperature for $15 \mathrm{~min}, 300 \mu \mathrm{l}$ supernatant (total protein extract) was used for precipitation of non-zeins by addition of ethanol to final concentration being $70 \%$. Resultant supernatant (zein protein solution) after centrifugation was dried in a SpeedVac and resuspended in $200 \mu \mathrm{l}$ of $\mathrm{ddH}_{2} \mathrm{O}$. $5 \mu \mathrm{l}$ was used for SDS-PAGE analysis of zein profile.

\section{DNA Isolation}

Leaf tissue was collected from individuals in backcrossing generations $\left(\mathrm{BC}_{1}\right.$ and $\left.\mathrm{BC}_{2}\right)$ for DNA extraction. DNA extraction was carried out using a BioSprint 96 workstation from Qiagen according to the user manual.

\section{Genotyping Using 02 in-gene Marker umc1066}

Polymerase Chain Reaction (PCR) was carried out in $20 \mu \mathrm{l}$ volume consisting of NEB Taq $0.15 \mu \mathrm{l}, 0.2 \mu \mathrm{M}$ dNTPs, $2 \mu \mathrm{l}$ standard Taq Reaction Buffer $(10 \times), 0.2 \mu \mathrm{M}$ forward/reverse primer of umc1066, template DNA $50 \mathrm{ng}$. PCR procedure was as follows: initial denaturation at $94^{\circ} \mathrm{C}$ for $4 \mathrm{~min}$ followed by 35 cycles of three steps including $94^{\circ} \mathrm{C}$ for $30 \mathrm{~s}, 57^{\circ} \mathrm{C}$ for $60 \mathrm{~s}, 72^{\circ} \mathrm{C}$ for $60 \mathrm{~s}$. Final elongation was done at $72^{\circ} \mathrm{Cfor} 10 \mathrm{~min}$. PCR products were visualized on $3 \sim 4 \%$ agarose gels. Individuals with $\mathrm{O} 202$ genotype were selected in backcrossing generations. This was also used for confirmation of 02 mutants in later generations $\left(\mathrm{BC}_{2} \mathrm{~F}_{2}, \mathrm{BC}_{2} \mathrm{~F}_{3}\right.$, and $\left.\mathrm{BC}_{2} \mathrm{~F}_{4}\right)$.

\section{Evaluation and Selection of Endosperm Modification}

Kernels were put embryo side down on a light box. Based on arbitrary visual estimation of the opaque endosperm proportion, kernels were classified into five types with Type I being fully vitreous, Type II being $\sim 25 \%$ opaque, Type III being $\sim 50 \%$ opaque, Type IV being $\sim 75 \%$ opaque and Type $\mathrm{V}$ being fully opaque.

\section{Amino Acid Profiling}

Samples for amino acids profiling analysis were ground together into a fine flour. Free amino acids (FAA) were extracted from 6 to $7 \mathrm{mg}$ of the flour pooled from 3 kernels of 3 $\mathrm{QPM}$ lines, 4 popcorn lines and the six $\mathrm{BC}_{2} \mathrm{~F}_{4}$ introgressions, while protein-bound amino acids (PBAA) were extracted from 3 to $4 \mathrm{mg}$. FAA were extracted and analyzed as described (Angelovici et al., 2013) using a UPLC-MSMS system (Xevo TQ-S from Waters Corporation). For the analysis of proteinbound amino acids (PBAA), acid hydrolysis (Fountoulakis and Lahm, 1998) was performed prior to the FAA extraction and LC-MS/MS analysis described above. Briefly, $200 \mu \mathrm{l}$ of $6 \mathrm{~N} \mathrm{HCl}$ was added to $\sim 4 \mathrm{mg}$ of flour and incubated for $24 \mathrm{~h}$ at $110^{\circ} \mathrm{C}$. Ten micro liters $(10 \mu \mathrm{l})$ were taken from the hydrolyzed samples and dried using a Savant SpeedVac concentrator (Fisher Scientific) before resuspension in the FAA extraction buffer and further analyzed as described (Angelovici et al., 2013).

\section{Quantitative Measurements of Pop Volume}

$\mathrm{BC}_{2} \mathrm{~F}_{5}$ samples along with corresponding popcorn parents were prepared and adjusted to same moisture content for quantitative popping. After popping treatment in an Orville Redenbacher Hot Air Popcorn Popper, a $200 \mathrm{ml}$ cylinder was used to measure the total volume.

\section{Total Protein Extraction and Relative Quantitation}

Total protein extract (as described in Total Zein Extraction) from $50 \mathrm{mg}$ kernel flour were diluted 250 times and $25 \mu \mathrm{l}$ of the diluted solution were used for Bicinchoninic Acid (BCA) protein assay. Protein concentration was assessed by the BCA assay kit (Pierce) according to the user's manual. Absorbances at $(\mathrm{OD}=562 \mathrm{~nm})$ were measured on a microplate reader Synergy2 (BioTek). Protein concentrations were determined from the BSA standard curve. Protein concentrations were compared between $\mathrm{BC}_{2} \mathrm{~F}_{4} \mathrm{QPP}$ introgressions with corresponding popcorn parents.

\section{Statistical Analysis}

Data were presented as Means \pm SEM. $P$-values less than 0.05 were considered significant. Principal Component Analysis (PCA) was carried out using R software.

\section{RESULTS}

\section{Quality Protein Popcorn Breeding Scheme}

Three QPM germplasms were selected as o2 donors which are CML 154Q, Tx807, and K0326Y (Gevers and Lake, 1992) (Supplementary Figures S1, S2 and Supplementary Table S1). Zein profiles of three QPMs and 11 popcorn lines (labeled as P1-P11 to preserve identity) are shown (Supplementary Figure S3). We initiated the introgression with two continuous backcrossing generations followed by four selfing generations (Figure 1). Because of the presence of Ga1-s in popcorns and gal in most dent corns, popcorns had to be used as male parents for cross initiation. Genotyping was carried out for 02 polymorphism across popcorn, QPMs and $\mathrm{F}_{1}$ crosses (Supplementary Table S2 and Supplementary Figures S4A,B). For the purpose of maintaining Gal-s, the resultant $\mathrm{F}_{1} \mathrm{~s}$ were backcrossed onto respective popcorn lines (recurrent parents). $\mathrm{F}_{2}$ populations were generated for evaluation of modifier transfer across different crosses (Supplementary Table S3). A scale for endosperm opaqueness was devised using a light box as described (Vivek et al., 2008; Supplementary Figure S5). From the $p$-value, the ratio of opaque to vitreous kernels in these $F_{2}$ ears deviates significantly from 1 to 3 implying that some 02 mutant kernels are fully or partially modified. $\mathrm{F}_{2}$ populations with small $p$-value were promising for modifier transfer. Small roundish popcorn kernels were observed in $\mathrm{F}_{2}$ populations. Popcorn phenotype vitreous kernels were selected for both SDSPAGE analysis and preliminary popping analysis to verify the presence of fully modified popcorn-like o2 mutants in the $\mathrm{F}_{2}$ 


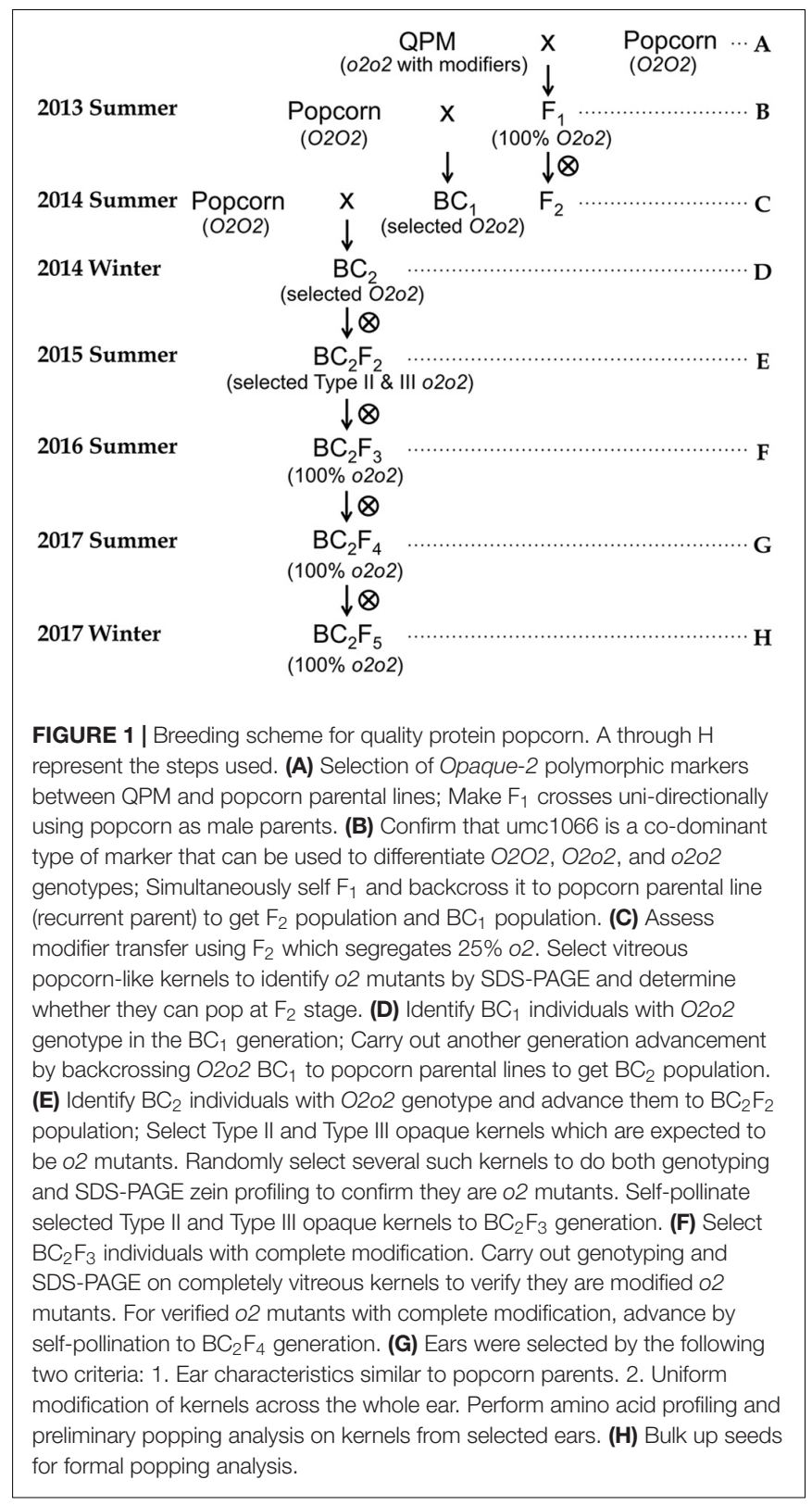

population (Supplementary Figure S6). A proportion of $\mathrm{F}_{2}$ popcorn-like kernels that were fully vitreous were obviously modified $o 2$ from their zein profiles. Furthermore, when such popcorn vitreous kernels were heated, 100\% (including 25\% o2/o2) popped showing proof-of-concept with only a single dose of popcorn. Individuals in backcrossing generations $\left(\mathrm{BC}_{1}, \mathrm{BC}_{2}\right)$ carrying the $o 2$ allele were screened by genotyping using umc1066 (Supplementary Figure S4C). $\mathrm{BC}_{2} \mathrm{~F}_{2}$ kernels harvested were assigned a level of modification on a scale defined in the $\mathrm{F}_{2}$ population (Supplementary Figure S5). In terms of genotype, they can be $o 2$ mutant with complete modification which is ideal. However they can also be heterozygous (O202) or homozygous (O2O2) with wild type phenotype. In order to guarantee the presence of 0202 genotype for later generation advancement

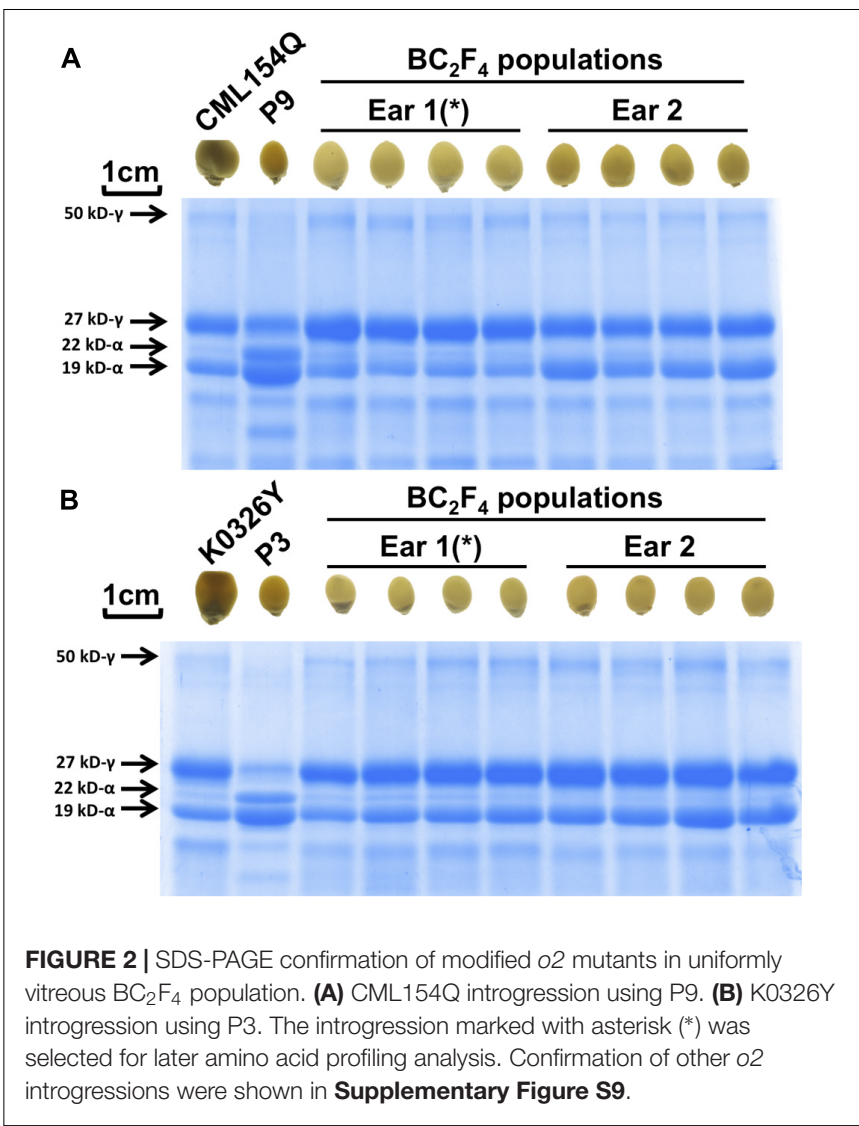

without the need to genotype all kernels, we selected Type II and Type III semi-opaque kernels from $\mathrm{BC}_{2} \mathrm{~F}_{2}$ populations for SDSPAGE zein profiling (Supplementary Figure S7). After Type II and Type III kernels were confirmed to be $02 / 02$ mutants, they were advanced into $\mathrm{BC}_{2} \mathrm{~F}_{3}$ and $\mathrm{BC}_{3}$ populations. In the $\mathrm{BC}_{2} \mathrm{~F}_{3}$ generation, ears with good modification were selected and used for characterization of completely vitreous popcornlike o2 mutants (Supplementary Figure S8). Candidate lines were advanced to the $\mathrm{BC}_{2} \mathrm{~F}_{4}$ generation. Analyses of the resultant $\mathrm{BC}_{2} \mathrm{~F}_{4}$ and $\mathrm{BC}_{2} \mathrm{~F}_{5}$ were carried out and provided proof of concept for the conclusion that QPP is achievable using the breeding strategy reported here.

\section{Confirmation of 02 Genotype in $\mathrm{BC}_{2} \mathrm{~F}_{4}$ Population With Full Modification}

We selected promising $\mathrm{BC}_{2} \mathrm{~F}_{4}$ ears with uniform modification (Figure 2 and Supplementary Figure S9A). SDS-PAGE gel analyses (Figure 2 and Supplementary Figure S9B) and umc1066 genotyping results of $\mathrm{BC}_{2} \mathrm{~F}_{3}$ (Supplementary Figure S8B) confirmed that all kernels were modified o2 mutants. Consistent with their vitreous appearance, they all have increased $27-\mathrm{kD} \gamma$-zein protein with respect to the wild type (popcorn parent) control. The uniformity in enhanced expression of $27-\mathrm{kD} \gamma$-zein implies that phenotypic selection alone is sufficient for the retention of this modifier QTL. $\mathrm{BC}_{2} \mathrm{~F}_{4}$ ears from selected modified Type I o2 kernels show more uniform modification than the $\mathrm{BC}_{2} \mathrm{~F}_{3}$ population, where there 


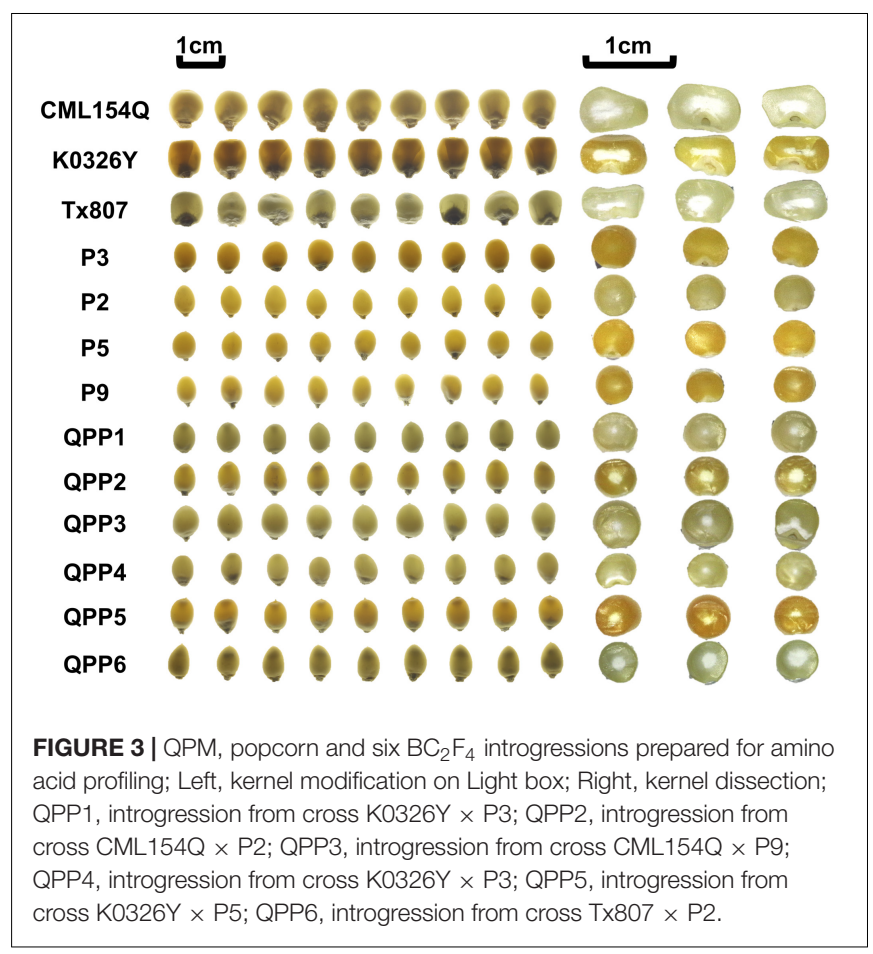

was more variability for modification in the ears. Because of lack of kernels for the Tx807 introgression which is also at an intermediate stage of modification restoration (Figure 3), it is not included for SDS-PAGE confirmation here (but included in later amino acids profiling to see the lysine difference).

\section{Amino Acids Profiling Revealed High Lysine in All Six $\mathrm{BC}_{2} \mathrm{~F}_{\mathbf{4}} \mathrm{O2}$ Introgressions}

In order to determine whether these popcorn-like 02 mutants have the high quality protein phenotype, amino acid profiling (both protein-bound amino acid and free amino acid) was carried out for six introgressions and parental lines including three QPM parents and four popcorn parents (Fountoulakis and Lahm, 1998; Angelovici et al., 2013). We also included B73 wild type and $\mathrm{B} 7302$ as dent corn controls for comparison to modified $\mathrm{BC}_{2} \mathrm{~F}_{4}$ samples. Vitreous endosperm content for the profiled kernels was shown by both light transmittance and by cutting kernels transversely (Figure 3). Here we included Tx807 $\mathrm{BC}_{2} \mathrm{~F}_{4}$ individuals, whose endosperm modification was not as advanced as other introgressions. Compared with wild type popcorn parental lines (P3, P2, P5, P9), all o2 mutants (QPMs, QPP introgressions) have a small opaque center. Compared with QPP1-QPP5, the amount of the central opaque region of QPP6 is larger. This is consistent with the fact that it is only partially modified currently and requires selection in future generation advancements. QPP1 and QPP4 had the least central opaque region, consistent with their vitreous appearance. For QPP3 and QPP4, the kernels had a slightly altered distribution of the opaque region. In total, sixteen amino acids were detectable and quantified for each sample. The nine kernels shown for each genotype represent three pools of three kernels (three biological replicates). The sixteen amino acids measurable were Ala, Arg, Aspx, Glx, Gly, His, Ile, Leu, Lys, Met, Phe, Pro, Ser, Thr, Tyr, and Val (Supplementary Table S4) where Glx is both glutamic acid and glutamine.

The results showed that all six introgressions have significantly increased content of both free lysine and protein-bound lysine compared with corresponding popcorn parents (Figure 4). The ratio of protein-bound lysine between QPPs and corresponding popcorn parental lines ranges from 1.45 fold (QPP5 compared with P5) to two-fold (QPP4 compared with P3). For free lysine, the ratio ranges from 4.05 fold (QPP3 compared with P9) to 12.3 fold (QPP6 compared with P2) (Supplementary Table S4). To extrapolate and display the global variation for all amino acids, we adopted the Principal Component Analysis (PCA) used in multivariate analysis (Figure 4C and Supplementary Figure S10). PCA using protein-bound amino acids data showed that the six introgressions grouped together with QPM germplasms in a distant group from popcorn parental lines (Figure 4C). This result suggests that the six introgressions have amino acid profiles similar to QPM. From the PCA biplot, the 15 amino acid (15 variables indicated as vectors) have different coordinations, implying different contribution to the total variation. Among the ones pointing toward the 02 group, four amino acids (Lys, His, Aspx, Arg) were positively correlated with 02 lines, whereas Leu, Tyr, Ile, and Ala were positively correlated with wild type germplasms. PCA analysis of free amino acids was also carried out and no clear pattern was observed across different $o 2$ mutants (QPM parents, QPPs, and B73o2) (Supplementary Figure S10). Previously, whole kernel amino acids contents were compared between 02 and wild type maize and showed the general lysine increase resulting from globally increased non-zein proteins (Hunter et al., 2002). Here, we compared the ratio of $o 2$ by wild type for 15 amino acids measured both in the above study and this study to see whether the above eight amino acids showed similar pattern between all $o 2$ and wild type samples (Supplementary Figure S11). This showed that the $\log 2$ value of the ratio of amino acid ( 02 by wild type) is consistently positive for Lys, His, and Arg, suggesting there is more of these amino acids in 02 background than in wild type backgrounds. In contrast, the $\log 2$ value of the ratio of amino acid ( 02 by wild type) was consistently negative for Met, Ser, Glx, Ala, Ile, Leu, and Phe. In both PCA biplot and comparative analysis of protein bound amino acid profile, Leu, Ile, Ala stand out as amino acids that are reduced in the $o 2$ background compared with wild type. Results of $\mathrm{BCA}$ protein assay on $\mathrm{BC}_{2} \mathrm{~F}_{4}$ populations indicated that there was no reduction in total protein in all six QPP germplasms (Supplementary Figure S12). Specifically, for QPP3 and QPP4, significant increases of total protein $(\alpha=0.05)$ was observed compared with corresponding popcorn parental lines.

\section{Selection of Fully Modified o2 Popcorn Can Result in Equivalent Popping to Popcorn Parents}

Small scale qualitative popping analysis on $\mathrm{BC}_{2} \mathrm{~F}_{4}$ kernels confirmed them to be fully poppable (not shown). After further bulking, $\mathrm{BC}_{2} \mathrm{~F}_{5}$ kernels were used for small scale quantitative 


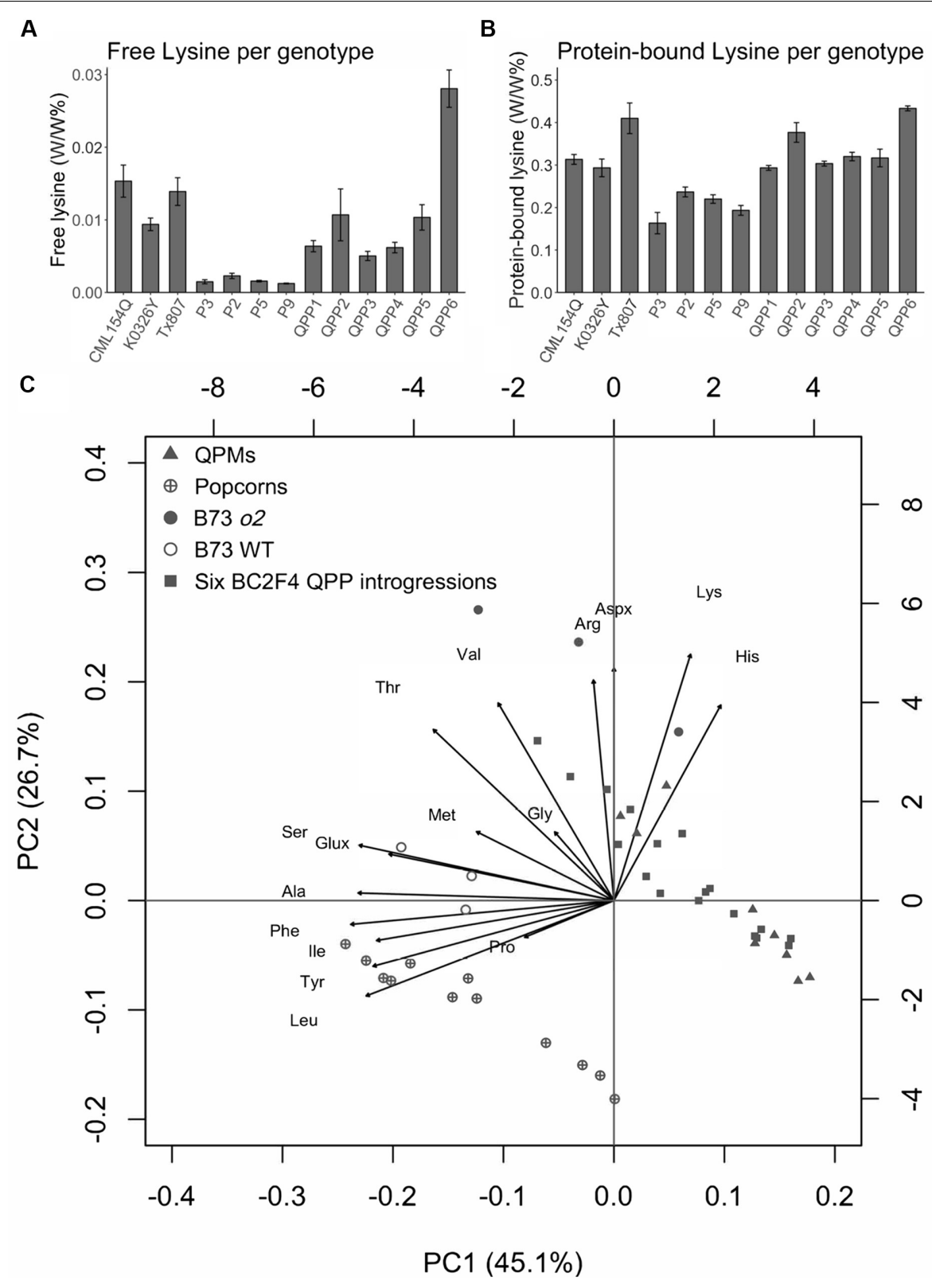

FIGURE 4 | Confirmation of high protein quality of six QPP $\mathrm{BC}_{2} \mathrm{~F}_{4}$ introgressions in comparison to QPM (CML154Q, K0326Y, and Tx807) and popcorn (P3, P2, P5, and P9) controls. (A) free lysine comparison. (B) protein-bound lysine comparison. (C) PCA analysis of protein bound amino acids. Principal component scores (PC1 and PC2) from each observation were plotted as dots in different shapes. Amino acids (variables) were plotted as arrows.

popping analysis (Figure 5A). To represent a general popping ability, three ears were selected which were the progeny of the $\mathrm{BC}_{2} \mathrm{~F}_{4}$ ears used for amino acid profiling. Three pools of kernels (3.33g each) were used as biological replicates for each ear. Percentages of popped kernels were above $90 \%$ for all QPP and Popcorn parental lines (Supplementary Table S5). Volume of the popped kernels were measured and used for pair-wise comparison with corresponding popcorn parental line (Supplementary Table S5 and Figure 5B). Comparisons that exhibited no significant difference are highlighted in bold in Supplementary Table S5 and bracketed in Figure 5B. There were no significant differences in the popping volume scores for QPP1-2 vs. P3 comparison $[t(3,2)=0.50, p=0.6495]$, QPP4-1 vs $\mathrm{P} 3$ comparison $[t(3,93)=-2.71, p=0.0544]$ and QPP2-3 vs. $\mathrm{P} 2$ comparison $[t(3,92)=-2.47, p=0.0699]$. Popping volumes equivalent to corresponding popcorn parents were achieved in these $\mathrm{BC}_{2} \mathrm{~F}_{5}$ populations (QPP1-2, QPP4-1, QPP2-3). For QPP1 and QPP4, where comparable popping volume was observed, the least residual proportion of opaque endosperm was observed. For QPP6, a mid-way introgression for which future selection of endosperm modification is required, the large residual region of opaque endosperm is contributing to reduced popping volume. 
A

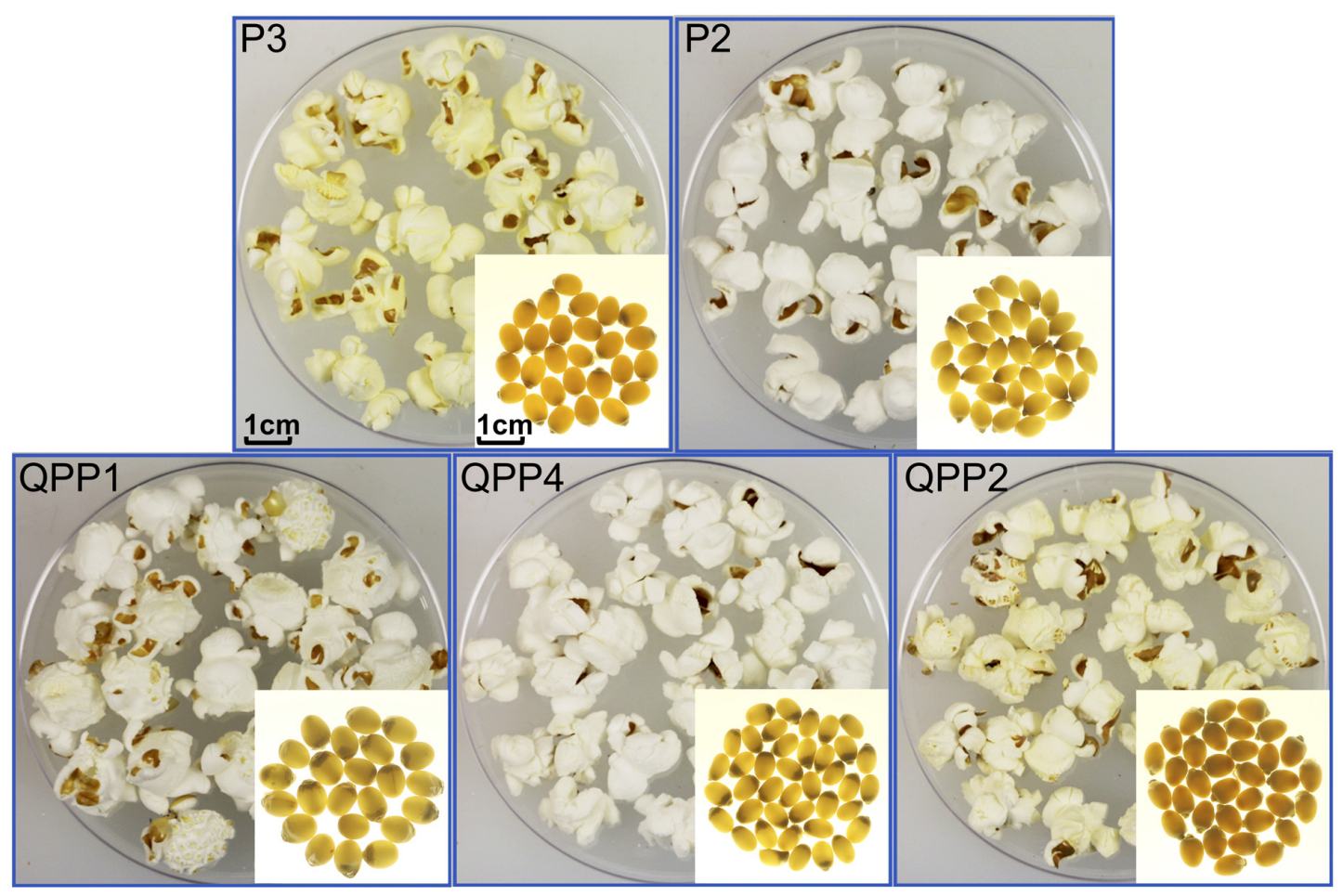

B

Comparison of popping volume $(\mathrm{ml})$

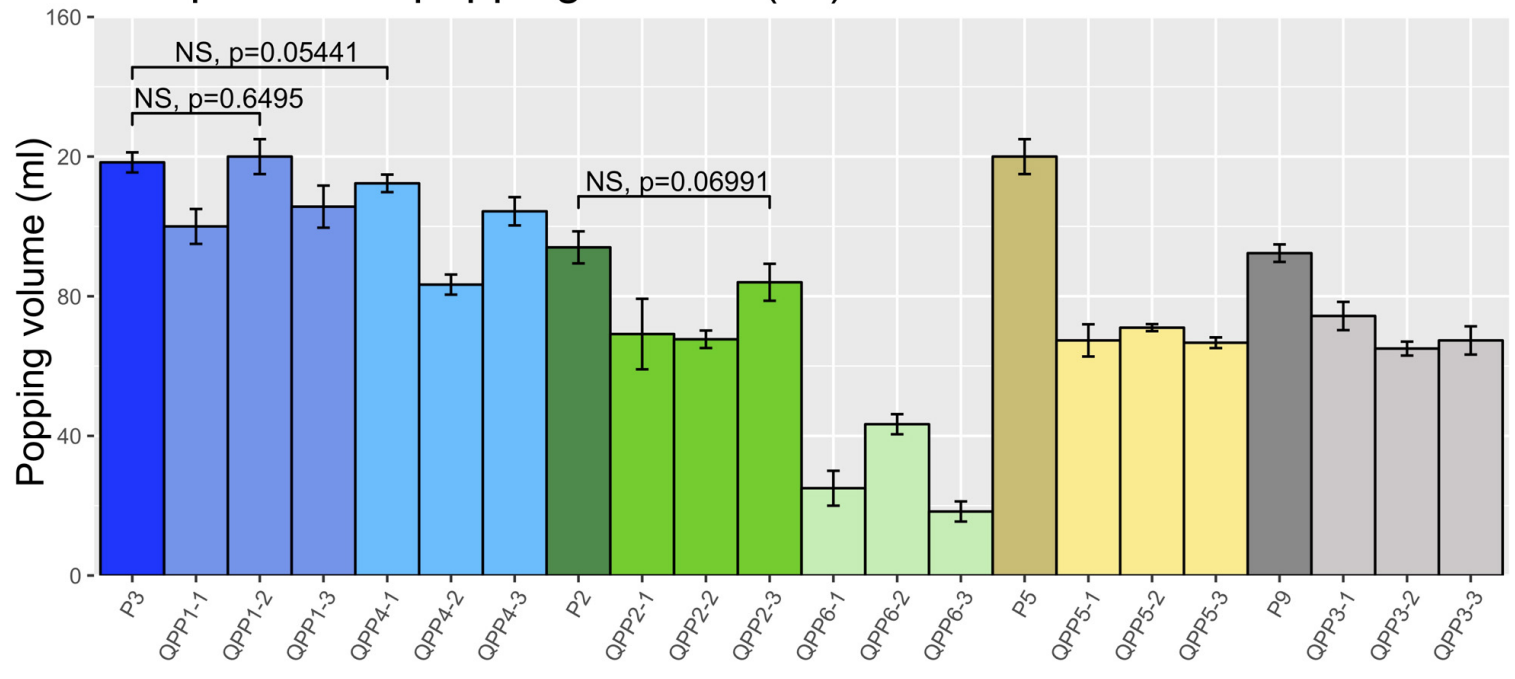

FIGURE 5 | Comparison of popping characteristics between QPP introgressions with corresponding popcorn parents. (A) kernels before and after popping (QPP1, $\mathrm{BC}_{2} \mathrm{~F}_{4}$ introgression from cross CML154Q $\times$ P3; QPP4, BC $2 \mathrm{~F}_{4}$ introgression from cross K0326Y $\times$ P3; $\mathrm{QPP} 2, \mathrm{BC} \mathrm{F}_{4}$ introgression from cross CML154Q $\times$ P2. (B) Popping volume comparison between QPPs and corresponding popcorn parental lines. Brackets between a popcorn parent and a QPP progeny indicate no significant differences.

\section{DISCUSSION}

Popcorn enjoyed nearly a constant increase in sales during the second half of the twentieth century (Sweley et al., 2013) in part due to innovations such as microwave popcorn but sales have since plateaued. Strategies for invigorating the popcorn industry should be multipronged and involve agronomic improvement and other aspects such as nutritional quality. QPP, with its natural opaque-2 and modifier alleles, and subsequent production of high yielding hybrids is one way improve the nutritional quality of 
popcorn and expand its realm. The development and utilization of more nutritious popcorn could have both economic and humanitarian application. Previous breeding focus on poppingrelated traits rather than plant agronomic traits, has resulted in much less agronomic improvement than in dent corn. For instance, yields of popcorn are less than dent corn (Ziegler, 2000). The agronomic superiority of dent corn has potential to contribute to popcorn improvements and led to several studies using crosses between dent corn and popcorn. Reduction of popping quality is commonly observed in dent corn by popcorn populations and thus is a major concern (Robbins and Ashman, 1984; Dofing et al., 1991; Lu et al., 2003; Li et al., 2006, 2009; Dhliwayo, 2008). However, studies confirmed that PEV could be partially recovered by backcrossing to popcorn parents while comparing the popping volume of $\mathrm{F}_{1}, \mathrm{BC}_{1}$, and $\mathrm{BC}_{2}$ populations (Crumbaker et al., 1949; Johnson and Eldredge, 1953). The complexity of the genetic loci contributing to PEV makes its maintenance challenging. Previously, it was reported that two generation backcrossing was sufficient to recover acceptable PEV (Crumbaker et al., 1949). The characteristic distinction in shape and size of kernels between popcorn and dent corn can be used for selection and accelerated recovery of popcorn genome. Using two generations of backcrossing combined with subsequent phenotypic selection for both kernel shape and ear characteristics, we selected inbred lines with comparable PEV to the original popcorn parents. Variation between $\mathrm{BC}_{2} \mathrm{~F}_{5}$ populations indicated that there is scope for further selection of PEV. Besides recovery of popping, for introgression of dent traits into commercial lines with cross-incompatibility, maintaining Ga1-s is essential to maintain popcorn's genetic isolation and ability to be grown in proximity to GM corn. We initiated $F_{1}$ crosses unidirectionally using popcorn parental lines as males and then used the $F_{1}$ and backcross generations as males to cross to popcorn females in subsequent generations. This ensured the maintenance of cross incompatibility between dent corn and popcorn since only pollen bearing the Ga1-s allele could successfully pollinate the popcorn recurrent parent.

As one way to avert protein malnutrition, many QPM conversion studies were carried out previously for dent corn (Babu et al., 2005; Gupta et al., 2009, 2013; Sofi et al., 2009; Jompuk et al., 2011; Krishna et al., 2017; Surender et al., 2017). Common challenges in QPM conversion programs included incomplete recovery of vitreous endosperm (modification), discontinuation of certain crosses from poor seed set and failure to improve lysine and tryptophan content (Moro et al., 1996; Prasanna et al., 2001; Vivek et al., 2008; Kostadinovic et al., 2016). Since popcorn kernels naturally have a very high proportion of vitreous endosperm (Figure 3), and this is the kernel region in which starch can melt during the popping process, complete endosperm modification is likely of paramount importance in QPM conversion into a popcorn background. o2 mutants without modification are associated with soft kernels and loss of popping as observed in several opaque-2 introgression studies (Zhou et al., 2016; Adunola, 2017). By evaluation of modifier transfer at the $F_{2}$ generation, we targeted crosses at an early stage, that had greater potential for later full restoration of vitreous, and likely poppable kernels. For these promising crosses, selection for endosperm modification was carried out on an individual basis in $\mathrm{BC}_{2} \mathrm{~F}_{2}$ generation (Type II and Type III opaque $\mathrm{BC}_{2} \mathrm{~F}_{2}$ individuals) and then on a whole ear basis in later generations $\left(\mathrm{BC}_{2} \mathrm{~F}_{3}, \mathrm{BC}_{2} \mathrm{~F}_{4}, \mathrm{BC}_{2} \mathrm{~F}_{5}\right)$. Selection of Type II and Type III opaque kernels at the $\mathrm{BC}_{2} \mathrm{~F}_{2}$ population is key step. The ongoing six $\mathrm{BC}_{2} \mathrm{~F}_{4} \mathrm{QPP}$ introgressions had, on average, four promising $\mathrm{BC}_{2} \mathrm{~F}_{2}$ populations segregating for Type I through Type IV opaqueness whereas the discontinued crosses were the ones which showed close to $25 \%$ Type IV-V (unmodified/opaque) kernels segregating in $\mathrm{BC}_{2} \mathrm{~F}_{2}$ populations.

Poor seed set has been observed in other QPM conversions throughout selection and can lead to the loss of targeted crosses (Kostadinovic et al., 2016). This phenomenon may be attributable to incompatibility between pollen and style. In our study, this was problematic in the $\mathrm{BC}_{2} \mathrm{~F}_{2}$. Although many crosses seemed promising for modifier transfer with significant $p$-values $(\alpha=0.05)$ in $F_{2}$ populations, because of poor seed set in the $\mathrm{BC}_{2} \mathrm{~F}_{2}$, we were not able to select enough Type II and Type III opaque $\mathrm{BC}_{2} \mathrm{~F}_{2}$ individuals for some crosses (Supplementary Table S3). Also, failure to improve lysine content was reported in some QPM conversions despite successful introgression of o2 and modifier genes (Moro et al., 1996; Babu et al., 2005; Vivek et al., 2008). However, this problem was not observed in any of our six $\mathrm{BC}_{2} \mathrm{~F}_{4}$ introgressions and the increases in both protein-bound lysine and free lysine were significant for all $\mathrm{BC}_{2} \mathrm{~F}_{4}$ QPP introgressions. RNA interference (RNAi) was adopted to reduce $22-\mathrm{kDa}$ and $19-\mathrm{kDa}$ zeins resulting in increased lysine ( $\mathrm{Wu}$ and Messing, 2011). The process of proteome rebalancing means that decrease of lysine devoid zein proteins will result in increased accumulation of lysine containing non-zeins (Wu and Messing, 2014). In addition to this global increase in non-zeins, it was shown that the most elevated nonzein proteins are enriched in lysine (Morton et al., 2015). For QPP to be useful, it is important that the kernels do not have reduced total protein. No total protein reductions were observed compared with either the popcorn or QPM parents and in fact, a significant increase in total protein is shown in two of our introgressions (Supplementary Figure S12). Most free amino acids are increased in QPP (Supplementary Table S4B) and this may be partly as a result of reduced incorporation into zeins. Substantial increases in the levels of most free amino acids were observed in several types of maize mutants with reduced zeins (Galili and Amir, 2013). However, since zeins do not contain lysine, this does not explain the increase in free lysine. The free amino acids increase was initially demonstrated in the 02 mutant. In addition to zein genes, $\mathrm{O} 2$ also regulates other genes including one encoding a lysine catabolic enzyme lysine-ketoglutarate reductase/saccharopine dehydrogenase (LKR-SDH) (BrochettoBraga et al., 1992; Kemper et al., 1999; Li et al., 2015). The resulting reduction in lysine degradation contributes to the observed free-lysine increase in 02 mutant. PCA of proteinbound amino acids indicated that the QPP introgressions grouped with QPMs but were distant from the group of wild type popcorn parents. Amino acids showing uniform increase (Asx, His, Lys, Arg) or decrease (Met, Ser, Glx, Ala, Ile, Leu, Phe) between all o2 (QPM parents, QPPs, and B73 o2) and all wild type germplasms (popcorn parents and B73) in this 
study were consistent with the comparison of amino acid composition between a wild type (W64A) and its isogenic line W64Ao2 (Hunter et al., 2002; Supplementary Figure S11). In the PCA analysis of free amino acids, wild type (popcorn parents, B73) were grouped together, whereas no obvious pattern were observed across different 02 mutants (QPM parents, QPPs, and B73o2) (Supplementary Figure S10).

In our breeding project, because of the simultaneous initiation of many cross combinations, it was unfeasible to genotype all parental lines in terms of cost and time. To recover popcorn genome, we used a continuous two-time backcrossing strategy (theoretically $87.5 \%$ genome recovered for recurrent parent), which is cost-efficient and was reported to generate acceptable PEV (Crumbaker et al., 1949). With respect to our priority for endosperm modification (high percentage vitreous endosperm recovery, which is itself a major characteristic of popping potential) since generation of $\mathrm{BC}_{2} \mathrm{~F}_{2}$, a direct evaluation of kernel vitreousness was carried out on the light box, without full knowledge of modifier QTLs for the QPM parents used. The increased uniformity in endosperm modification observed from $\mathrm{BC}_{2} \mathrm{~F}_{2}$ to $\mathrm{BC}_{2} \mathrm{~F}_{4}$ indicated that the modifiers likely reached homozygosity during this process. In $\mathrm{BC}_{2} \mathrm{~F}_{4}$ populations tested with SDS-PAGE, the uniformly increased level of $27 \mathrm{kD} \gamma$-zein protein likely indicates that the allelic composition $27 \mathrm{kD}$ $\gamma$-zein locus reached homozygosity for the duplicated allele. This process for recovery of endosperm modification would presumably have been longer, had we prioritized high percentage of popcorn parent genome along the breeding process. By combining backcrossing and phenotypic selection, generation advancement was carried out cost-effectively for multiple crosses simultaneously.

The strategy outlined here for introgression of dent corn traits into popcorn backgrounds brings together selection for QPM (o2 and modifier genes) and for popcorn characteristics (cross-incompatibility conferred by Ga1-s, kernel shape, high proportion of vitreous endosperm), resulting in the first proof-ofconcept demonstration that development of QPP is achievable. The six $\mathrm{BC}_{2} \mathrm{~F}_{4}$ introgressions between three QPMs and four

\section{REFERENCES}

Adunola, P. M. (2017). Introgression of Opaque-2 Gene Into the Genetic Background of Popcorn Using Marker Assisted Selection. Master's thisis, Federal University of Technology, Akure.

Angelovici, R., Lipka, A. E., Deason, N., Gonzalez-Jorge, S., Lin, H., Cepela J., et al. (2013). Genome-wide analysis of branched-chain amino acid levels in arabidopsis seeds. Plant Cell 25, 4827-4843. doi: 10.1105/tpc.113.11 9370

Babu, B. K., Agrawal, P., Saha, S., and Gupta, H. (2015). Mapping QTLs for opaque2 modifiers influencing the tryptophan content in quality protein maize using genomic and candidate gene-based SSRs of lysine and tryptophan metabolic pathway. Plant Cell Rep. 34, 37-45. doi: 10.1007/s00299-014-1685-5

Babu, R., Nair, S. K., Kumar, A., Venkatesh, S., Sekhar, J. C., Singh, N. N., et al. (2005). Two-generation marker-aided backcrossing for rapid conversion of normal maize lines to quality protein maize (QPM). Theor. Appl. Genet. 111, 888-897. doi: 10.1007/s00122-005-0011-6

Babu, R., and Prasanna, B. (2014) "Molecular breeding for quality protein maize (QPM)," in Genomics of Plant Genetic Resources, eds R. Tuberosa, A. Graner, and E. Frison, Dordrecht: Springer, 489-505. popcorn parents, all carrying the homozygous 02 allele, give excellent scope for QPP hybrid production and testing which has begun.

\section{DATA AVAILABILITY}

All data generated or analyzed during this study are included in this published article and its supplementary information files.

\section{AUTHOR CONTRIBUTIONS}

YR and DH designed the research. All authors performed the research. YR, AY, RA, and DH analyzed the data. YR and DH wrote the paper.

\section{FUNDING}

This work was funded by ConAgra Foods.

\section{ACKNOWLEDGMENTS}

We thank ConAgra Foods for its support in funding and providing popcorn germplasms and North Central Regional Plant Introduction Station for providing QPM germplasms for research. We also thank Devin Rose for input during the conceptualization phase of this project. We are grateful to Christine Smith, Kyla Morton, Shangang Jia, and Aixia Li for help with field work.

\section{SUPPLEMENTARY MATERIAL}

The Supplementary Material for this article can be found online at: https://www.frontiersin.org/articles/10.3389/fpls.2018.01803/ full\#supplementary-material

Brochetto-Braga, M. R., Leite, A., and Arruda, P. (1992). Partial purification and characterization of lysine-ketoglutarate reductase in normal and opaque2 maize endosperms. Plant Physiol. 98, 1139-1147. doi: 10.1104/pp.98.3. 1139

Collard, B. C., and Mackill, D. J. (2008). Marker-assisted selection: an approach for precision plant breeding in the twenty-first century. Philos. Trans. R. Soc. B 363, 557-572. doi: 10.1098/rstb.2007.2170

Crumbaker, D. E., Johnson, I., and Eldredge, J. (1949). Inheritance of popping volume and associated characters in crosses between popcorn and dent corn. Agron. J. 41, 207-212. doi: 10.2134/agronj1949.00021962004100050009x

Dhliwayo, T. (2008). Genetic Mapping and Analysis of Traits Related to Improvement of Popcorn. Ph.D. thesis, Iowa State University, Ames, IA.

Dofing, S. M., D’Croz-Mason, N., and Thomas-Compton, M. A. (1991). Inheritance of expansion volume and yield in two popcorn $\times$ dent corn crosses. Crop Sci. 31, 715-718. doi: 10.2135/cropsci1991.0011183X003100030035x

Erazo-Barradas, M. (2009). Evaluation of Popping Expansion Traits in a Maize (Zea mays L.) Population. Master's thesis, Iowa State University, Ames, IA.

Fountoulakis, M., and Lahm, H. W. (1998). Hydrolysis and amino acid composition analysis of proteins. J. Chromatogr. A 826, 109-134. doi: 10.1016/ S0021-9673(98)00721-3 
Galili, G., and Amir, R. (2013). Fortifying plants with the essential amino acids lysine and methionine to improve nutritional quality. Plant Biotechnol. J. 11, 211-222. doi: 10.1111/pbi.12025

Geetha, K., Lending, C. R., Lopes, M. A., Wallace, J. C., and Larkins, B. A. (1991). opaque- 2 modifiers increase $\gamma$-zein synthesis and alter its spatial distribution in maize endosperm. Plant Cell 3, 1207-1219.

Gevers, H. O., Lake, J. K. (1992). "Development of modified opaque-2 maize in South Africa," in Quality Protein Maize, ed. E. T. Mertz, Saint Paul, MN, AACC, 49-78.

Gupta, H. S., Agrawal, P. K., Mahajan, V. Bisht, G. S., Kumar, A., and Verma, P. (2009). Quality protein maize for nutritional security: rapid development of short duration hybrids through molecular marker assisted breeding. Curr. Sci. 96, 230-237.

Gupta, H. S., Raman, B., Agrawal, P. K. Mahajan, V., Hossain, F., and Thirunavukkarasu, N. et al. (2013). Accelerated development of quality protein maize hybrid through marker-assisted introgression of opaque-2 allele. Plant Breed. 132, 77-82. doi: 10.1111/pbr.12009

Holding, D. R. (2014). Recent advances in the study of prolamin storage protein organization and function. Front. Plant Sci. 5:276. doi: 10.3389/fpls.2014. 00276

Holding, D. R., Hunter, B. G., Chung, T., Gibbon, B. C., Ford, C. F., and Bharti, A. K., et al. (2008). Genetic analysis of opaque2 modifier loci in quality protein maize. Theor. Appl. Genet. 117, 157-170. doi: 10.1007/s00122-008$0762-y$

Holding, D. R., Hunter, B. G., Klingler, J. P. Wu, S., Guo, X., Gibbon, B. C., et al (2011). Characterization of opaque2 modifier QTLs and candidate genes in recombinant inbred lines derived from the K0326Y quality protein maize inbred. Theor. Appl. Genet. 122, 783-794. doi: 10.1007/s00122-010-1486-3

Hoseney, R., Zeleznak, K., and Abdelrahman, A. (1983). Mechanism of popcorn popping. J. Cereal Sci. 1, 43-52. doi: 10.1002/anie.201402040

Hunter, B. G., Beatty, M. K., Singletary, G. W., Hamaker, B. R., Dilkes, B. P., Larkins, B. A., et al. (2002). Maize opaque endosperm mutations create extensive changes in patterns of gene expression. Plant Cell 14, 2591-2612. doi: 10.1105/tpc.003905

Johnson, I., and Eldredge, J. (1953). Performance of recovered popcorn inbred lines derived from outcrosses to dent corn. Agron. J. 45, 105-110. doi: 10.2134/ agronj1953.00021962004500030005x

Jompuk, C., Cheuchart, P., Jompuk, P., and Apisitwanich, S. (2011). Improved tryptophan content in maize with opaque-2 gene using marker assisted selection (MAS) in backcross and selfing generations. Kasetsart J. 45, 666-674.

Kemper, E. L., Neto, G. C., Papes, F., Moraes, K. C., Leite, A., and Arruda, P. (1999). The role of Opaque 2 in the control of lysine-degrading activities in developing maize endosperm. Plant Cell 11,1981-1993. doi: 10.1105/tpc.11.10. 1981

Kostadinovic, M., Ignjatovic-Micic, D., Vancetovic, J., Ristic, D., Bozinovic, S., Stankovic, G., et al. (2016). Development of high tryptophan maize near isogenic lines adapted to temperate regions through marker assisted selectionimpediments and benefits. PLoS One 11:e0167635. doi: 10.1371/journal.pone. 0167635

Krishna, M., Reddy, S. S., and Satyanarayana, S. D. (2017). Marker-assisted breeding for introgression of opaque-2 allele into elite maize inbred line BML-7. 3 Biotech 7:165.

Li, Y., Dong, Y., Niu, S., and Cui, D. (2007). QTL for popping characteristics in popcorn. Plant Breed. 126, 509-514. doi: 10.1111/j.1439-0523.2007.01 372.X

Li, Y. L., Dong, Y. B., Niu, S. Z., and Cui, D. Q. (2009). Identification of QTL for popping characteristics using a BC2F2 population and comparison with its F2:3 population in popcorn. Agric. Sci. China 8, 137-143. doi: 10.1016/S16712927(09)60020-1

Li, Y. L., Dong, Y.B., and Niu, S. Z. (2006). QTL analysis of popping fold and the consistency of QTLs under two environments in popcorn. Acta Genet. Sin. 33, 724-732. doi: 10.1016/S0379-4172(06)60105-4

Li, C., Qiao, Z., Qi, W., Wang, Q., Yuan, Y., Yang, X., et al. (2015). Genome-wide characterization of cis-acting DNA targets reveals the transcriptional regulatory framework of opaque2 in maize. Plant Cell 27, 532-545. doi: 10.1105/tpc.114. 134858

Liu, H., Shi, J., Sun, C., Gong, H., Fan, X., Qiu, F., et al. (2016). Gene duplication confers enhanced expression of $27-\mathrm{kDa} \gamma$-zein for endosperm modification in quality protein maize. Proc. Natl. Acad. Sci. U.S.A. 113, 4964-4969. doi: $10.1073 /$ pnas. 1601352113

Lu, H. J., Bernardo, R., and Ohm, H. W. (2003). Mapping QTL for popping expansion volume in popcorn with simple sequence repeat markers. Theor. Appl. Genet. 106, 423-427. doi: 10.1007/s00122-002-1041-y

Manna, R., Okello, D., Imanywoha, J., Pixley, K., and Edema, R. (2005). Enhancing introgression of the opaque- 2 trait into elite maize lines using simple sequence repeats. Afr. Crop Sci. J. 13, 215-226.

Mbuya, K., Nkongolo, K., and Kalonji-Mbuyi, A. (2011). Nutritional analysis of quality protein maize varieties selected for agronomic characteristics in a breeding program. Int. J. Plant Breed. Genet. 5, 317-327. doi: 10.3923/ijpbg. 2011.317.327

Mertz, E. T., Bates, L. S., and Nelson, O. E. (1964). Mutant gene that changes protein composition and increases lysine content of maize endosperm. Science 145, 279-280. doi: 10.1126/science.145.3629.279

Moro, G. L., Habben, J. E., Hamaker, B. R., and Larkins, B. A. (1996). Characterization of the variability in lysine content for normal and opaque2 maize endosperm. Crop Sci. 36, 1651-1659. doi: 10.2135/cropsci1996. 0011183X003600060039x

Morton, K. J., Jia, S., Zhang, C., and Holding, D. R. (2015). Proteomic profiling of maize opaque endosperm mutants reveals selective accumulation of lysine-enriched proteins. J. Exp. Bot. 67, 1381-1396. doi: 10.1093/jxb/ erv532

Panda, A. K., Raju, M. V., and Rao, S. V. Lavanya, G., Pradeep Kumar Reddy, E., Shyam Sunder, G., et al. (2010). Replacement of normal maize with quality protein maize on performance, immune response and carcass characteristics of broiler chickens. Asian Aust. J. Anim. Sci. 23, 1626-1631. doi: 10.5713/ajas. 2010.10036

Prasanna, B. M., Vasal, S. K., Kassahun, B., and Singh, N. N. (2001). Quality protein maize. Curr. Sci. 81, 1308-1319.

Robbins, W. A., and Ashman, R. B. (1984). Parent-offspring popping expansion correlations in progeny of dent corn $\times$ popcorn and flint corn $\times$ popcorn crosses. Crop Sci. 24, 119-121. doi: 10.2135/cropscil 984 . 0011183X002400010027x

Schnable, P. S., Ware, D., Fulton, R. S., Stein, J. C., Wei, F., Pasternak, S., et al. (2009). The B73 maize genome: complexity, diversity, and dynamics. Science 326, 1112-1115. doi: 10.1126/science.1178534

Sofi, P., Wani, S. A., Rather, A., and Wani, S. H. (2009). Quality protein maize (QPM): genetic manipulation for the nutritional fortification of maize. J. Plant Breed. Crop Sci. 1, 244-253.

Surender, M., Reddy, S. S., Sudarshan, M. R., and Durgarani, C. V. (2014). Gene specific SSR marker for detection of OPAQUE-2 alleles for conservation of non-QPM lines for QPM development. Res. J. Agric. Sci. 5, 666-669.

Surender, M., Shetti, P., Sagare, D. B., and Durga Rani, C. V. Jabeen, F., Sudarshan, MR., Sokka Reddy, S., et al. (2017). Development of QPM version of DHM117 maize hybrid using marker assisted selection. Int. J. Curr. Microbiol. App. Sci. 6, 3275-3289. doi: 10.20546/ijcmas.2017.610.384

Sweley, J. C., Rose, D. J., and Jackson, D. S. (2013). Quality traits and popping performance considerations for popcorn (Zea mays Everta). Food Rev. Int. 29, 157-177. doi: 10.1080/87559129.2012.714435

Vielle-Calzada, J. P., Martínez de la Vega, O., Hernández-Guzmán, G., IbarraLaclette, E., Alvarez-Mejía, C., Vega-Arreguín, J. C., et al. (2009). The palomero genome suggests metal effects on domestication. Science 326, 1078-1078. doi: $10.1126 /$ science. 1178437

Vivek, B., Krivanek, A., Palacios-Rojas, N., Twumasi-Afriyie, S., And Diallo, A. O. (2008). Breeding Quality Protein Maize (QPM): Protocols for Developing QPM Cultivars. Texcoco: CIMMYT.

Walbot, V. (2008). Maize genome in motion. Genome Biol. 9:303. doi: 10.1186/gb2008-9-4-303

Wallace, J. C., Lopes, M. A., Paiva, E., and Larkins, B. A. (1990). New methods for extraction and quantitation of zeins reveal a high content of gamma-zein in modified opaque-2 maize. Plant Physiol. 92, 191-196 doi: 10.1104/pp.92.1.191

Wu, Y., Holding, D. R., and Messing, J. (2010). $\gamma$-zeins are essential for endosperm modification in quality protein maize. Proc. Natl. Acad. Sci. U.S.A. 107, 1281012815. doi: 10.1073/pnas.1004721107

Wu, Y., and Messing, J. (2011). Novel genetic selection system for quantitative trait loci of quality protein maize. Genetics 188, 1019-1022. doi: 10.1534/genetics. 111.131078 
Wu, Y., and Messing, J. (2014). Proteome balancing of the maize seed for higher nutritional value. Front. Plant Sci. 5:240. doi: 10.3389/fpls.2014. 00240

Young, V.R., Scrimshaw, N.S., Pellett, P. (1998). "Significance of dietary protein source in human nutrition," in Feeding a World Population of More Than Eight Billion People: A Challenge to Science, ed. J. C. Waterlow, Oxford: Oxford University Press, 205-222.

Zhou, Q., Shi, Q. L., and Dong, Y. B. (2016). Effect of opaque-2 gene on grain, quality and popping characteristics of popcorn. J. Henan Agric. Sci. 45, 24-28.

Ziegler, K. E. (2000). "Popcorn," in Specialty Corn, 2nd edn, ed. A. R. Hallauer, Boca Raton FL: CRC Press, 199-234.
Conflict of Interest Statement: The authors declare that the research was conducted in the absence of any commercial or financial relationships that could be construed as a potential conflict of interest.

Copyright $\odot 2018$ Ren, Yobi, Marshall, Angelovici, Rodriguez and Holding. This is an open-access article distributed under the terms of the Creative Commons Attribution License (CC BY). The use, distribution or reproduction in other forums is permitted, provided the original author(s) and the copyright owner(s) are credited and that the original publication in this journal is cited, in accordance with accepted academic practice. No use, distribution or reproduction is permitted which does not comply with these terms. 